\title{
Digital Environmentalism: A Case Study of PM2.5 Pollution Issue in Chinese Social Media
}

\author{
Yanshuang Zhang ${ }^{1}$ \\ ${ }^{1}$ School of Communication and Arts, The University of Queensland, Brisbane, Australia \\ Correspondence: Yanshuang Zhang, School of Communication and Arts, The University of Queensland, \\ Brisbane, Australia. Tel: 61-452-199-626. E-mail: y.zhang22@uq.edu.au
}

Received: September 16, $2016 \quad$ Accepted: February 13, 2017 Online Published: February 16, 2017

doi:10.5539/jms.v7n1p76 URL: http:/doi.org/10.5539/jms.v7n1p76

\begin{abstract}
The emergence of social media over the last decade has substantially altered not only the means people communicate with each other but also the whole online ecosystems. For the common public in particular, social media enables and broadens the social conversation that anyone interested can engage in on urgent social problems such as environmental pollution. In China, the ever-thickening air pollution smothering most urban cities in recent years has provoked a nationwide discussion, and popular social media like Weibo has been fully utilised by various social actors to participate in this "green speak". This paper examines the civil discourse about the deteriorating air pollution on China's largest microblogging platform-Sina Weibo, and seeks to understand how different social actors respond to and reconstruct the reality. Through a discourse analysis aided by a text analytics/ visualisation software-Leximancer, this paper investigates the civil discourse from three angles: the demographics, the discursive strategies and the potential social effect. The result suggests that proactive civil engagement in this issue has produced an environmental discourse with a wide range of topics involved, and that the benign interactions between social actors could give rise to a proactive interactional mode between Chinese state and civil society which would definitely be beneficial to the democratisation process in contemporary China.
\end{abstract}

Keywords: digital environmentalism, social media, air pollution, civil discourse, proactive interaction, Weibo, China

\section{Introduction}

Since its reform and opening up in 1978, China has witnessed a thriving economy that makes it a global economic superpower. However, this prosperity has been achieved at the expense of environmental sustainability and by taking a route of "polluting first and cleaning up later". In recent decades, the consequences of the unsustainable economic growth have come into play as the natural and ecological environment is subjected to tremendous and irreversible degradation.

Despite the state's efforts in making environmental protection policies over decades, politics still tends to give priority to the economy, especially when the country's economic development is in full swing. Environmental policies often remain on paper because they are poorly implemented with rare coordination and endeavour of all relevant departments at national, provincial and local levels. Lo \& Fryxell (2003) attribute this political ambiguity to China's long-established fragmented bureaucracy, political obstruction of the more powerful ministries and a shortage of resources. Theoretically speaking, China has never had a shortage of environmental policies and laws in place that should have been able to alleviate the deteriorating environment; however, their effectiveness of these policies and laws rests on the government's adherence to them.

Researchers believe that the relationship between environmentalism and the economy is not a zero-sum gain (Schofer \& Granados, 2006). Nonetheless, in China, the economy always wins in terms of political priority. The decentralisation of power and jurisdiction in current political reforms has given considerable autonomy and flexibility to local governments and private sectors in many fields. However, this political decentralisation also makes it more difficult for the central government to carry out macro-control over environmental issues in general because the devolution of political power to local levels entitles the local governments to discretionary authority in environmental policies.

As one consequence of this political decentralisation, local protectionism has become an umbrella for collusion 
between local governments and businesses, and has severely circumscribed the force of environmental regulations. For instance, in China, many township enterprises laden with pollution survive and thrive with little punishment from local environmental bureaus because they are major contributors to local economic development. The local governments believe that closing them down would lead to vast unemployment and social unrest, which would hinder the promotion of local officials. Some local governments even ask the environmental bureaus to cover up for polluting companies by tampering with environmental monitoring reports provided to the higher-ups. For the same reason, local governments usually ignore companies that have foreign investment and are ostracized by their home countries due to their environmental infractions ( $\mathrm{Li}, 2013)$.

The green economy is a new mode of economy that results in reducing environmental risks and ecological scarcities, and that aims for sustainable development without degrading the environment. It requires more investment in green apparatus and substantial resources to process waste and pollutants in industries. Since the 11th Five-Year Plan (2006-2010) was carried out, China had taken considerable steps to shift to a low-carbon growth strategy and allocated significant shares of investments to green sectors; in its 12th Five-Year Plan (2011-2015), one of the key themes is protect the environment and shift from a high resource-consuming economy to a green economy. However, the continuing conflict between economic development and environmentalism has become the most challenging roadblock to the application of the new green initiative. So far the practice of the green economy by and large remains marginalised in most regions, and on rare occasions, officials have been held to account for nonfeasance in environmental issues.

The mode of economic development with high capital investment, resource consumption and pollution discharge may result in short-term prosperity, but in the long run, it has catastrophic consequences for both the economy and the environment. The experience of many developed countries indicates that a country can actually get more benefit from a pro-environmental economy that is guaranteed by a mature and effective environmental-protection mechanism. The establishment of such a mechanism relies not only on the strict implementation of existing environmental policies, but also on a relatively wide public support and a robust civil society.

Nowadays, there is a new trend happening in public counteraction towards environmental issues. With the aid of the Internet and social media such as Weibo, Chinese citizens are enabled to employ more peaceful ways to resist the government, including online petitions and campaigns, and offline organised protests that do not aim to challenge the regime. Compared to the physical places that are highly monitored by the state apparatuses, Internet and social media have offered an alternative channel for protest and signatory campaigns. The government also becomes more tolerant to such incidents as long as they are constrained in a scope of control. On one hand, technically it is actually impossible to eliminate online gatherings. On the other, for the government, there is not much to gain in alienating the core segment of Chinese civil society that it needs the most in its economic modernisation campaigns. So we have reason to believe that the increasing public opposition to environmental degradation could spur the government to reform environmental management, and in the course of negotiating with all stakeholders involved, the government may achieve the delicate balance between economic growth and environmental protection.

\section{Environmentalism in Social Media}

The use of social media and mobile applications for personal interaction enables the creating and sharing of user-generated content, and thereby, changes the ways we learn, perceive and think about the world we live in. Cox (2013) describes six ways that social media can change environmental communication: (1) environmental information and buzz, (2) green communities and social networking, (3) reporting and documenting, (4) public criticism and accountability, (5) mobilising, and (6) micro-volunteering and self-organising. This description comprehensively covers the wide range of social media usage by journalists, environmental non-governmental organisations (ENGOs), public agencies and individuals for environmental advocacy.

The interactivity between the organisations and supporters may lead to greater civil involvement by constructing an online "civic commons" and providing policy advice for the government (Hemmi \& Crowther, 2013).

In China's context, with the environment deteriorating along the fast industrialisation, mass environmental protests have increased $29 \%$ per year since 1996, and by a staggering $120 \%$ in 2012, according to Yang Zhaofei, vice-chair of the Chinese Society for Environmental Sciences. Before social media was invented, protesters had utilised the Internet and mobile phones to initiate and organise campaigns that addressed the local environmental issues of concern. Now Chinese citizens are increasingly turning to social media, such as Sina Weibo, to vent their anger over environmental pollution, and the government has been forced to respond to these public interrogations. A green public has been emerging, along with frequent large-scale public debates on 
environmental issues. Among these debates, the PM2.5 issue is the most remarkable one in recent years.

PM or particulate matter, is the term for particles found in the air, including dust, dirt, soot, smoke, and liquid droplets. PM2.5 particles are air pollutants with a diameter of 2.5 micrometres or less, small enough to invade even the smallest airways; they are referred to as "fine" particles and are believed to pose the greatest health risks. PM2.5 is held to be a more accurate reflection of air quality than other standards of measurement, but information about it had never previously been made available to the public in China before 2012 .

The public debate on PM2.5 first began on Weibo in December 2011, when it became known that air-quality monitoring results released by Beijing's weather-forecast station and the U.S. Embassy in Beijing often differed. While the results from the embassy often described Beijing's air quality as "hazardous" or "dangerous", the Beijing weather-forecast station would describe the pollution as "minor". Both sources defended their stances by saying that the difference resulted from using different measurement standards, which even caused diplomatic conflict (XinhuaNews, 2012). The online public opinion urged the government to apply the tighter PM2.5 standard. In February 2012, the State Council added PM2.5 to the newly revised National Ambient Air Quality Standard and applied it to dozens of pilot cities.

Statistics from China's Ministry of Environmental Protection (MEP) indicate that cities in China's three key industrial and developed regions, the Beijing-Tianjin-Hebei area, the Yangtze River Delta and the Pearl River Delta, suffer over 100 haze days every year with PM2.5 concentration two to four times above the World Health Organisation guidelines. The heated public discussion over PM2.5 led to its installation as a new national indicator for air-quality monitoring, as well as a new Airborne Pollution Prevention and Control Action plan (2013-2017), which was issued in early 2013 with a focus on those three geographical areas, and would be backed by 1,700 billion yuan (about 260 million US dollars) governmental investment. Yet, public health risks and economic loss caused by PM2.5 continue to be of great public concern as long as the "airpocalypse" constantly appears in more and more Chinese cities.

When record-breaking smog again shrouded north-eastern China in January 2013, one year after the State Council applied the stricter PM2.5 standard to Chinese urban cities, the public knew about it instantly from Weibo thanks to the sharing from the pollution-monitoring apps on their smart phones; as a result, the central government rolled out new anti-pollution measures within days (Hook, 2013). In fact, in cities around the world, social media have given committed air-quality campaigners a powerful tool for drawing attention to an issue whose profile remains relatively low despite its big impact on urban dweller's health (Gardiner, 2014).

For ENGOs and other environmental groups, social media has also enabled them to provide professional knowledge and advice for the public and industries, and expedited the rise of Chinese environmental movements that push for more informational transparency in environment quality and monitor the environmental governance of the authorities. For instance, following the air-quality crisis this case study starts with, a former journalist, political blogger and dissident, Michael Anti, set up a project named "China Air Daily". This project updates photos and satellite pictures of select cities in China as records of the improvement or deterioration of air quality in these cities. Civic organisations as the Institution of Public \& Environmental Affairs have also monitored the Chinese environment through mapping out the water, air and solid waste pollution in most Chinese cities over the years.

The World Health Organization estimates that dirty air prematurely kills more than six million people a year. In China, a cooperative study published in 2012 by Peking University and environmental group Greenpeace estimated that there were 8,572 premature deaths in Shanghai, Guangzhou, Xi' an and Beijing in 2010 that could be attributed to PM2.5 air pollution; the study also found that this number would keep increasing year by year (Greenpeace, 2012). Therefore, it is no accident that this deadly environmental issue has drawn high attention from the whole Chinese society and fostered a green civil discourse that incubates pluralistic views on environmental issues and engages citizens in politics and public policy without being primary political (Calhoun \& Yang, 2007). And the proliferation of environmental discourse, or to use Calhoun and Yang's term, a greenspeak, will finally depend on the participation from a range of civil society actors including citizens, the traditional media, social media and ENGOs.

The key to understanding the role of social media in the framing of environmental issues lies in how online public discourse comes to be understood as facilitating environmental discourse and online/offline green campaigns, and possibly inducing institutional or policy changes. And this paper represents an effort in this direction.

\section{Data and Methods}

This case study attempts to answer three questions: what information are ordinary Chinese citizens keen to share 
on their public space about the air quality? How do different groups of actors communicate their concerns in the public discourse? And what further implications does this civil discursive engagement have to the emerging green public and Chinese society. To this end, I used "PM2.5" as the search term and traced the public discussion on Sina Weibo for one month (from 1 January to 31 January, 2014). The valid data for analysis is mainly focused on text rather than other media formats that coexist on Weibo, such as images, audio and video. Pictures, emoticons, videos and audio files were intentionally left out during processing. Overall, the researcher obtained 25,000 posts for further analysis.

I also engaged in participant observation throughout the project as an active Weibo user and media consumer. My relevant knowledge and a comprehensive understanding of the issue under study were developed through close attention to the evolution of the issue on both social media and the traditional media over a period of time. Apart from Weibo posts, I also looked closely at other media data, such as news articles in the mainstream media, which is indispensable to my deeper understanding of the phenomenon despite not serving as the direct analytic target in this case study.

Since the data collected from Weibo are mainly texts, the approach will be discourse-analytical, which means the public discourse is not treated as mere messages whose content is analysed in a superficial, quantitative way. Rather, I examine the complex structures and strategies of online public discourse and its relations to the social context. In this case, the social context consists of the online and offline activities of ordinary citizens, ENGOs as well as the government's response to citizens' concerns in the increasingly democratic Chinese society. More specifically, by conducting a systematic investigation of online discourse, I attempt to figure out what role the social media in general, and online public discourse in particular, plays in the reproduction of greenspeak in Chinese civil society.

The data analysis is carried out from a discoursal analytical approach to examine how the public discourse framed the environmental issues and how the involved civil society actors made sense of the online civil discourse and constructed a reality of their own. With ample empirical textual examples from the online civic discourse, the case study aims to map out a concrete construction process of the green public emerging from the issue-specific online civil discourse.

\section{Results}

\subsection{A Benign Communication Chain Composed of Various Social Actors}

The social actors represented in the sample data can be recognised by their belonging categories of the Weibo identity verification system. Sina Weibo's identification is like Twitter's verified account, which verifies the identity of famous people, organisations and so on. Once a user gets through the verification on the Internet, a coloured "V" will be added behind their username. An orange "V" is for people, while a blue one is for organisations and companies. Also, there will be a graph and a declaration on its user page to show the verification. There are several kinds of verifications: individual (e.g., a celebrity), university, organisation, government departments, media platforms and companies.

In this case, the typology of involved actors can be attributed to three categories: individual actor, organisation actor, and media actor. The distribution of the 20,728 posts contributed by each category is shown in Table 1 .

Table 1 . The distribution of posts by user category

\begin{tabular}{lll}
\hline User category & Post counts & Percentage \\
\hline Individual actors & 17663 & $85 \%$ \\
Organisational actors & 1355 & $6 \%$ \\
Media actors & 1710 & $9 \%$ \\
\hline
\end{tabular}

The individual actors, in this case, include users with personal verification, and a lot of others without any verification. Individual actors are ordinary citizens vis-à-vis government or other social organisations, in spite of the fact that celebrities, activists, and public opinion leaders may also exert wide influence on the public discourse as the institutional users do. A large proportion (85\%) of public discourse about the air-quality issue has been contributed by ordinary citizens. That is to say, Weibo has provided an open platform for public discussions about social problems and has made these discussions accessible to a wider civil engagement.

In day-to-day civil discoursal practices, only a small number of individual posts can gain remarkable attention from the public. Yet the wider participation of ordinary citizens is still indispensable to retain their core mission of acting as watchdogs, ethical guardians and advocates of the marginalised or under-represented. For example, 
the residents in rural areas who are severely affected by environmental pollution but do not have access to the Internet or possess enough online skills to voice their concerns. Such practice is quotidian, but very valuable in that, collectively, it can urge the government to acknowledge the problems and respond with possible countermeasures.

In some cases, certain individuals may act in the public interest as whistle-blowers, holding institutions or officials to account, and may spark a larger public debate. Pan Shiyi (@panshiyi), the business celebrity who first pointed out the divergence in PM2.5 readings between the U.S. Embassy in Beijing and the local weather-forecast authority, is a good example of such whistle-blowers. The "common good" they stand for, their professional competence in seizing and analysing information, and their large social networks, make these people very likely to become noteworthy opinion leaders who can positively influence the public agenda and shape the environmental debate with aligned interest groups.

Governmental and non-governmental organisations (organisational actors), such as commercial organisations and other civil institutions, also make use of social media to promote their interests or advocate their causes by releasing information and mobilizing citizens. From Table 1, it is clear that such organisations only contribute 6\% of all input into the public discourse on the PM2.5 issue. But this does not mean the organisational actors have failed to engage themselves in these issues and monitor the environmental governance of the regime. In fact, these actors, especially the ENGOs, have fully utilised the Internet to disseminate information and mobilise other peer groups and ordinary citizens to negotiate with the government on the issue. Some examples of the actions of organisational actors include calling on the government to publish data on sources of pollution (not limited to air pollution) and making such information more transparent and accessible to the public (Song, 2014).

Among many others, Greenpeace and its regional branches nationwide, for example, have published on Weibo both generic information such as updated news, and professional knowledge such as research reports on air pollution. Similarly, local environmental groups, from the Institute of Public \& Environmental Affairs (IPE) to Greenbreath, also regularly publish air-monitoring results and other relevant information about environment protection. Different from individual actors that focus on personal experience and instant emotion in their content, organisational actors are often more able to access local knowledge, expertise and insight to reach the goal, improve credibility of environmental activities and provide socially and environmentally responsible policy references.

Local environmental protection bureaus (EPBs) are an important force in shaping the public discourse on environmental issues. However, local EPBs have been in an awkward position between the state and market since China's GDP-oriented economic growth model has rendered China's environmental governance a centrally planned one (Carter \& Mol, 2006). They are heavily dependent on (in both administrative and financial terms) higher-level environmental authorities and on local governments, which often turn a blind eye to local enterprises' environmental violations for the sake of local economic prosperity. Little importance is given to environmental criteria in assessing the performance of local governments, and limited empowerment is given to the environmental authorities (Lotspeich \& Chen, 1997). Therefore, Weibo has provided an unprecedented opportunity for these institutions to play the dual role of providing authoritative information and monitoring environmental violations to increase their visibility in public environmental issues and get away from the traditional "straw man" image. (Note 1)

Many traditional media outlets have opened official accounts (media actors) on Weibo. These official accounts tend to not only extend the content of their original prints to the Weibosphere but also develop their own reportage guidelines in accordance with social media's unique characteristics. With regard to the air-quality issue, the media actors, though accounting for a minor $9 \%$ of the sample posts, informed the audience of the latest environmental measures or policies initiated by governments at all levels, and actually played the role of intermediary between the governments and the common public.

In mainland China, all media outlets including the state-run media and independent media are administered by various government agencies and regulators. Self-censorship is widely employed by designated editors to make sure the content is "ideologically right" before publication. When Weibo is 80tilized by these media actors, many topics that were discarded by print media outlets due to their sensitiveness or page limits now have a chance to go public. Albeit still guided by their respective censorship policies, these media accounts obtain more freedom on Weibo because they undertake the responsibility of demonstrating a new image of a more open, democratic government.

People's Daily, the official newspaper of the Party, usually provides information and discussion on the policies and viewpoints of the government, mostly from positive angles. However, its Weibo account @People'sDaily 
occasionally criticizes the government with surprisingly candid content. Back to the pollution issue, People's Daily once posted:

[MicroEditorial: how many "state secrets out there] The soil pollution data, state secret; the information about the meeting for formulating new Raw Milk Standard, state secret...... "State secret", is like a maxim for "refusing to be open". Is it really involved in classified information, or just because the information may provoke public discontent? At the very beginning of SARS and PM2.5 dispute, they both were treated as unspoken secrets. Now people freely discuss them and nothing bad actually happens. Covering up only makes people speculate that they are tricked.

Compared with the mass media's conventional way of disseminating information, the intermediary role of these media actors on social media is more prominent. This is because they not only run a news service aligned with their traditional guidelines, but also produce more freestyle news that caters to the common social media audience members who wish not to be fed by top-down information flow, but rather, an equal, dialogic communication. Therefore, the discourse they represent to guide public opinion includes more than just the official views; they also provide the views of the populace to add affinity and diversity to the public discourse.

\subsection{Diversified Language Rhetoric and Discursive Strategies}

As indicated above, a benign communication chain constituted by the ordinary citizens, media, environmental organisations and environmental authorities has been formed. They accordingly assume different duties in this process. Specifically, ordinary citizens retain their quotidian mission of acting as watchdogs, ethical guardians and advocates of marginalised or under-represented interests. Environmental organisations monitor environmental governance, work with other peer groups and mobilise citizens to participate in all kinds of environmental causes. For the governmental institutions, Sina Weibo has provided a platform for them to provide authoritative information, increase their visibility in public issues and get away from their long-standing negative image of nonfeasance. Media actors, including both the government mouthpieces and other outlets, play an intermediate role in creating a dialogic space between the government and the civil society.

These actors accordingly used different discursive strategies to fulfil their commitment in the public discourse. Despite the difference between the language and rhetoric used by different categories of actors, they all show conformity to the nature of social media and adopt a language style that is brief, instant and casual. In general, Weibo users tended to vent their feelings about the daily air quality in an instant, personalised way, and through the language choices, their posts created a negative picture of the air conditions in their home cities.

Most users tended to publish air-quality readings when the air quality turned out to be not that good. So a large proportion of posts strongly expressed residents' dissatisfaction with the air they breathe in every day. And the choice of language and rhetoric formations overall gives a negative representation of the air-pollution issue. For instance, this negative representation can be manifested by the repeated use of negative words when related to air quality, such as "polluted", "harmful", "unhealthy", "severe", "serious", "heavily", "bad", "worse", "suffering" and "choking". Such negative words were employed thousands of times (an estimate of 7,889 times) throughout the data, compared with the much less frequent use of positive words like "good" or "healthy" (an estimate of 349 times).

There were many complaints about the polluted air, but many other posts conveyed a neutral sentiment or positive messages, such as those about a new air-pollution control policy, or bringing forth their optimistic expectation of such policies. As a result, the sentiment analysis of the data turns out neutral on the whole and the public discourse remains in a rational spectrum, highlighting the element of reason that is embedded in a healthy public sphere in civil society.

Different discursive strategies are adopted by different social actors to frame a certain reality, which in this case study, is a reality of air pollution in China. The framing as an action involves the selection and composition of the facts, opinions and values, and by organising discourse, guides the social actors to produce their own meanings about this social phenomenon. In the following paragraphs, these strategies are explained and illustrated by first-hand examples.

Citizens depoliticise political issues. In this case study, the citizen users on Weibo tended to be apolitical when discussing the air-pollution issue, even though the issue per se is in fact very political. De-politicalizing the issue can avoid attracting the censors' gaze: users just record something quotidian or vent their instant feelings, and do not intend to put forward any political claims about it (see Table 2). 
Table 2. Examples of citizens' discursive strategies

\begin{tabular}{|c|c|c|}
\hline No. & Example post & Process \\
\hline 1 & $\begin{array}{l}\text { Beijing's PM } 2.5 \ldots \text { Even though it's a nice day, my face is still stained with a lot of black } \\
\text { dust. Feel a bit clean only after washing my face twice with facial bar. }\end{array}$ & $\begin{array}{l}\text { Realise PM2.5's harm to health } \\
\text { (e.g., skin problems) }\end{array}$ \\
\hline 2 & $\begin{array}{l}\text { Recently Chongqing has been often shrouded by smog, who can tell me how much PM2.5 } \\
\text { it contains? Today I got something amazing: TFBOYS mask! Mum, don't worry about my } \\
\text { flu any more. The mask can protect me from PM } 2.5 \text { ! }\end{array}$ & $\begin{array}{l}\text { Action of protection (e.g., using } \\
\text { mask) }\end{array}$ \\
\hline 3 & $\begin{array}{l}\text { Every night this restaurant makes this road have a strong smell of BBQ because its boss } \\
\text { used a formidable electric exhaust fan. I liked BBQ very much but now thinking of PM2.5 } \\
\text { I usually avoid this road... }\end{array}$ & $\begin{array}{l}\text { Condemn activities that } \\
\text { contribute to pollution (e.g., } \\
\text { BBQ) }\end{array}$ \\
\hline 4 & $\begin{array}{l}\text { Recently the air pollution is really severe. But I often see some people burn rubbish off the } \\
\text { street. Today I saw a woman started to burn her rubbish so I went over and told her to stop } \\
\text { burning rubbish any more. But when I left she resumed again. People's environmental } \\
\text { awareness is really low. Next time when I travel on bicycle, I will wear a T-shirt with the } \\
\text { slogan: In order to reduce PM } 2.5 \text { and protect environment, please don't burn rubbish on } \\
\text { site. }\end{array}$ & $\begin{array}{l}\text { Protest activities that contribute } \\
\text { to pollution (e.g., burning } \\
\text { rubbish) }\end{array}$ \\
\hline 5 & $\begin{array}{l}\text { The noise of firecrackers outside has silenced the television. This is the real atmosphere of } \\
\text { Spring Festival. However, the result of this jubilation is: tomorrow's PM2.5 reading will } \\
\text { be off the chart! }\end{array}$ & $\begin{array}{l}\text { Question cultural traditions that } \\
\text { contribute to pollution (e.g., } \\
\text { setting off fireworks during } \\
\text { Chinese New Year) }\end{array}$ \\
\hline
\end{tabular}

By describing how PM2.5 or its related activities have been affecting their personal lives in the offline lifeworld, ordinary Chinese citizens position themselves as the sufferer/victim of the deteriorating environment, which, unavoidably, can be attributed to a degree of government malfunction. However, it seems that the citizens tend not to question the political actors on this issue, but rather, narrate a specific situation without imputation. It is also worth noting that this strategy is not necessarily carefully planned. The mental organisation of such a process may range from automatic to highly conscious (Wodak, 1999).

Although citizens were keener to share their personal experience or feelings about a particular issue on Weibo, from another perspective, their messages still showed their relationship to wider cultural and social frameworks. Through the frequent act of reporting air-quality readings, these citizens constructed the issue as a nasty hassle that they had to deal with daily and tried every means to fight against.

Other social actors such as scientists and public officials are also involved as citizen groups in this case study. But they are not just common citizens. Scientists can utilise their professional knowledge to testify, and lead to important investigations of, and debates about, environmental problems affecting human health. Sometimes environmental scientists' research is disputed or misinterpreted, as indicated by some examples in this case study; therefore, effective science communication has also become an issue that matters to a healthy green public sphere. Public officials as individuals are at the heart of the political and legislative process because they must reconcile the arguments and interests of the diverse voices speaking for or against specific environmental policies (Cox, 2013). Usually less visible to the public due to their governmental position, public officials' participation in the public discourse is supposed to be a balancing act between contending forces of various interest groups including the government, industries and the general public.

Media build responsibility. As an intermediary between the state and civil society, the media actors have, on one hand, conveyed informational messages to the public, and on the other, attempted to build responsibility for both the citizens and governmental institutions, which can be viewed as the media's intrinsic responsibility. To achieve this purpose, the media actors usually inform people of particular critical facts, or persuade people into action. In this case study, media actors constructed the air-pollution issue as a serious, urgent social problem that needed responsibility and action from both individuals and the government (see Table 3). 
Table 3. Examples of media's discursive strategies

\begin{tabular}{|c|c|c|}
\hline No. & Example post & Process \\
\hline 1 & $\begin{array}{l}\text { [Experts: poor quality face masks are more dangerous than haze] recently nationwide smog has sieged } \\
\text { Chinese people. PM2.5 face mask has become popular thanks to people's rising awareness of health. } \\
\text { However, some experts warn that poor quality masks may delay the right protective measures and } \\
\text { what's worse is they may cause more harm to people's health with secondary pollution. }\end{array}$ & Inform harm \\
\hline 2 & $\begin{array}{l}\text { [smoking } 3 \text { cigarettes indoor results in PM } 2.5 \text { exceeding } 30 \text { times of the standard]Today the National } \\
\text { Health and Family Planning Commission declared to promote the tobacco control legislation. Warning: } \\
\text { lighting a cigarette in a } 15 \mathrm{~m}^{2} \text { room will increase PM } 2.5 \text { concentration from } 32 \mu \mathrm{g} / \mathrm{m}^{3} \text { to } 1100 \mu \mathrm{g} / \mathrm{m}^{3} \\
\text { instantly; Lighting } 3 \text { cigarettes will increase the number to } 2248 \text {, exceeding } 30 \text { times of the national air } \\
\text { quality standard. It will take } 16 \text { hours' ventilation to go back to normal. Please quit smoking for your } \\
\text { health! }\end{array}$ & $\begin{array}{lr}\text { Persuade } & \text { people into } \\
\text { action } & \text { (quitting } \\
\text { smoking) } & \end{array}$ \\
\hline 3 & $\begin{array}{l}\text { [During "two sessions" citizens are most concerned with how to control haze] the annual sessions of } \\
\text { the Shanghai Municipal People's Congress and the Shanghai Committee of the Chinese People's } \\
\text { Political Consultative Conference are drawing near. What issues are people and representatives } \\
\text { concerned with? The report of Jiefang Daily conducted man-on-the-street interviews and found "air", } \\
\text { "transportation", "food safety", "housing price" were most frequently mentioned. An 83-year-old party } \\
\text { member hoped the representatives to tell the truth rather than lies; community residents looked up at } \\
\text { the sky, and said they were very concerned with PM2.5. }\end{array}$ & $\begin{array}{l}\text { Inform } \\
\text { concerns }\end{array}$ \\
\hline 4 & $\begin{array}{l}\text { On the first day of new year, many places of the province came across the hotbed weather for } \\
\text { haze- heavy fog. Do you still want to set off firecrackers to worsen this situation? Yesterday the } \\
\text { real-time AQI of Zhengzhou increased from } 216 \text { at } 9 \mathrm{am} \text { to } 291 \text { at } 7 \mathrm{pm} \text {, with PM2.5 index increasing } \\
\text { from } 130 \text { at } 7 \mathrm{am} \text { to } 241 \text { at } 5 \mathrm{pm} \text {. Please set off fewer firecrackers to protect our health. The } \\
\text { anti-firecracker action is underway; the fresh air is not far. By Dahe Daily journalist Zhukun. }\end{array}$ & $\begin{array}{l}\text { Persuade people out of a } \\
\text { certain behaviour } \\
\text { (setting off firecrackers) }\end{array}$ \\
\hline 5 & $\begin{array}{l}\text { [Beijing municipal government's thanks to citizens: PM2.5 index lower than expected] According to } \\
\text { Beijing Daily, today Beijing municipal government released an open letter to thank the citizens for } \\
\text { responding to its call for setting off fewer fireworks and firecrackers to reduce air pollution. "On New } \\
\text { Year's Eve, less fireworks and firecrackers were set off, and the resulting injuries and fires decreased } \\
\text { remarkably. The PM2.5 index was lower than expected...Here sincere thanks to all the citizens!" }\end{array}$ & $\begin{array}{l}\text { Inform the effect of } \\
\text { action, persuading more } \\
\text { people into action }\end{array}$ \\
\hline
\end{tabular}

News media not only report the air-pollution issue and warn the public of the harm it may do to human health, but also attempt to build its responsibility of persuading people into environmental protection, such as quitting smoking, and decreasing the consumption of fireworks. On the other hand, the media have an intermediary role between the officials and the populace: the media can inform the officials of the people's concerns about the environmental crisis and spur policy changes at the institutional level.

The news media not only report environmental events and convey information to the public, but also attempt to influence public attitudes through their agenda-setting function. Since news journalism usually has a criterion of newsworthiness towards events (Boyd, 1994), the media often filter or select issues for attention and choose how to frame or package a news story based on their agreed news values. While most environmental topics are less dramatic, news media usually only focus on some prominent stories rather than the trivial aspects of quotidian life. In terms of air pollution, for instance, the crisis has actually existed for a long time. But in this case study, extensive news media, including the official media outlets, began to step in and cover the issue, not only because of the severity of the problem but also because it had already provoked a collective protest from a considerable proportion of the population. Suffice it to say, social media combined with mobile applications has greatly assisted the public opinion to reach such a tipping point.

ENGOS deliver profession and legitimacy. Focusing on education and volunteerism, environmental organisations disseminate information regarding environmental sustainability and organise environmental protection activities. In China, environmental organisations are best described as "governmental non-governmental organizations" (Schwartz, 2003, p. 36) because they are mostly established and funded by government agencies. Apart from educating the general public, these government-sponsored organisations also undertake the responsibilities of educating government officials at various levels and broadening their scope of knowledge of environmental issues. Therefore, these organisations' public discourse on Weibo usually conveys authoritative knowledge to the public, and legitimises environmental issues as both politically and socially important issues that need to be treated seriously and urgently (see Table 4). 
Table 4. Examples of ENGOs' discursive strategies

\begin{tabular}{|c|c|c|}
\hline No. & Example post & Process \\
\hline 1 & $\begin{array}{l}\text { As showed by the pollution monitoring system of Hebei Environment Protection Authority, there are still } \\
\text { factories discharging excessive pollutants even when PM } 2.5 \text { reading is off the charts. From } 12 \mathrm{am}-2 \mathrm{pm} \text { on } \\
16 \text { January, in the most polluted Shijiazhuang, Langfang and Baoding, } 6 \text { factories were still discharging } \\
\text { excessive pollutants. Oh dear, it's already off the charts, how could you persist in discharging pollutants } \\
\text { beyond limit?! }\end{array}$ & $\begin{array}{l}\text { Quote official } \\
\text { information, question } \\
\text { illegal act }\end{array}$ \\
\hline 2 & $\begin{array}{l}\text { Where does PM2.5 in Beijing come from?-Regarding the online discussion about the research report } \\
\text { published by the Chinese Academy of Science on the chemical components of PM } 2.5 \text { in Beijing, and } \\
\text { whether the report truthfully reflects the source of PM } 2.5 \text { pollution in Beijing, @invisibleFatguy as the } \\
\text { head of Climate and Energy Campaign from Greenpeace will answer these questions to help citizens } \\
\text { better understand the findings in the research report. For more details see image. }\end{array}$ & $\begin{array}{l}\text { Bring in expert } \\
\text { opinion, legitimise } \\
\text { scientific research }\end{array}$ \\
\hline 3 & $\begin{array}{l}\text { Is \#Smog in Xi'an\# different from that in other cities? Greenpeace and The School of Public Health of } \\
\text { Peking University released a report-Dangerous Breath, investigating the harm PM2.5 has brought to } \\
\text { Chinese urban citizens' health. Based on the readings in 2010, Xi'an was no better than the heavily } \\
\text { polluted Beijing and Shanghai, and confronts a tough task of curbing air pollution. Download the } \\
\text { complete report here: http://t.cn/zj90yvc }\end{array}$ & $\begin{array}{l}\text { Quote authoritative } \\
\text { research, legitimise } \\
\text { appeal for action }\end{array}$ \\
\hline 4 & $\begin{array}{l}\text { [PM2.5 national ranking this morning] Good morning. News from } \\
\text { Guardian: Study estimates that in } 2011 \text { there were } 26 \text { million people in China shortened their life } \\
\text { expectancy due to the combustion of coal. Coal burning had led to } 320,000 \text { children and } 61,000 \text { adults } \\
\text { with asthma, and } 36,000 \text { newborns underweight. The study tracked coal combustion, airborne chemicals, } \\
\text { and found they were very hazardous to health. }\end{array}$ & $\begin{array}{l}\text { Quote authoritative } \\
\text { news sources }\end{array}$ \\
\hline 5 & $\begin{array}{l}\text { \#Truth of Smog\#-Research on PM2.5 pollution in Jing-Jin-Ji Area and Reduction Strategies shows that: } \\
\text { Coal emission of atmospheric pollutants is the greatest source of smog across Beijing, Tianjin and Hebei. } \\
\text { In terms of industries, coal, steel, and cement are the first pollutant, the emission of which includes soot, } \\
\text { sulphur dioxide, nitrogen oxides and volatile organic compounds, constituting the main sources of smog } \\
\text { and haze. More details: http://t.cn/8kIZMJC }\end{array}$ & $\begin{array}{l}\text { Quote authoritative } \\
\text { research }\end{array}$ \\
\hline
\end{tabular}

Environmental organisations often quote credible officials, experts, scholars and other organisations to bring credibility and authoritativeness to their statements, and add professionalism and correctness to their content on Weibo, a site where less professional or even erroneous news stories are widely broadcast. The purpose of doing this is eventually to legitimise their position in educating both the public and government officials, and most importantly, in promoting environmental causes and mobilizing civil participation in the public agenda of environmental protection.

Environment-related issues, such as public health rights and social justice advocated by environmental organisations, are also main topics of civil discourse. Apart from conveying environmental information to the lay public, these organisations also initiate a wide array of both online and offline campaigns. Diverse issues are addressed by environmental groups, not limited to air pollution. And for different issues, the strategies of their advocacy often differ. For example, in this case study, Greenpeace mainly published research reports and provided expert knowledge about pollution as its routine discourse practices on Weibo; local environmental groups such as the IPE and the China Air Quality Observation mainly collected updated pollution data and disclosed it to the public, and monitored and exposed polluting enterprises. The networked nature of social media suggests a more vigorous circulation of discourse among these environmental organisations and the general public. Supplementing the traditional environmental websites, mailing lists and forums, social media easily aggregate allied environmental organisations and recommend packaged information to interested users.

\subsection{Proactive Civil Discursive Participation in a Wide Range of Topics}

The data analysed in this case study were Weibo posts published by thousands of users on Sina Weibo throughout January 2014. Each post was within the limit of 140 Chinese characters and had a username followed by the content, which was either originally produced, or editorializing and forwarding others' posts. The original posts also included information about the release time, location, platform ( $\mathrm{PC} / \mathrm{mobile})$ or application people used to send the messages through.

By the time of writing, the search results for "PM2.5" on Weibo have reached 23 million posts, unfolding a resourceful and active environmental discourse in the online public sphere. The sample data contains around 25,000 posts, which could present the dynamics of public discourse in one month and reveal part of the landscape of the Chinese green public and environmental discourse. 

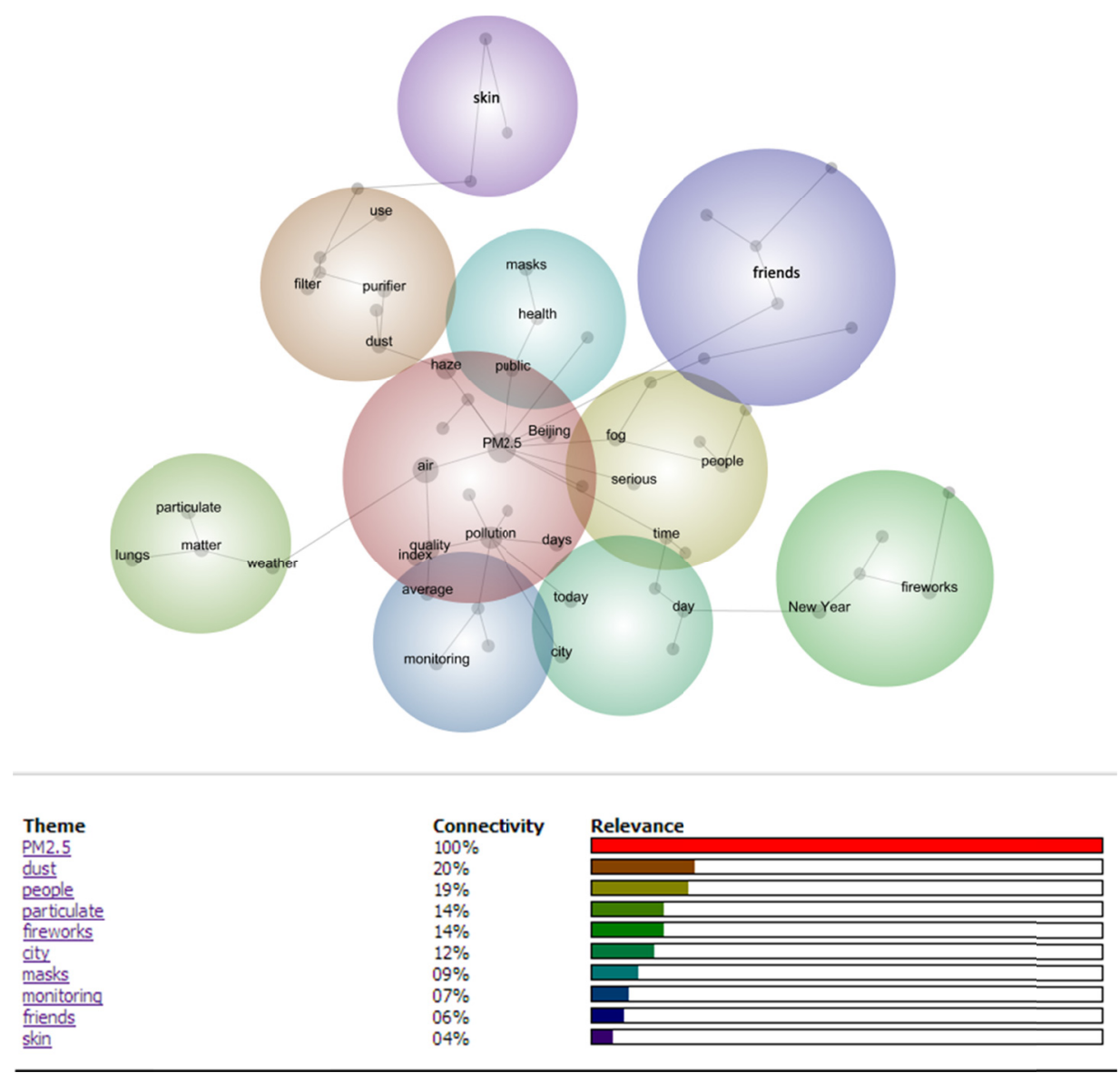

Figure 1. The concept map and thematic summary

Figure 1 captures the main themes and concepts that emerged from the public discourse about the PM2.5 issue on Weibo, and reflects the topical issues that people are concerned with. Chinese citizens' awareness of air pollution and environmental protection, in general, has been remarkably raised after the Beijing PM2.5 dispute of late 2011. The manifestation of this civil awareness is threefold in the data.

First, public monitoring of urban air quality has become a routine practice. The relevant concepts in the concept map are "people", "city" and "monitoring". By using weather applications on mobile phones or keeping a close eye on PM2.5 monitoring websites, citizens have tended to develop a strong awareness of the environmental pollution in their home cities through a simple "sharing" behaviour, and collectively have urged the Chinese authority to take more effective measures to curb the deteriorating situation.

Second, realising the threat polluted air poses to public health, Chinese citizens have begun to initiate individual actions, such as wearing masks and using household air filters in their daily lives. The relevant concepts are "masks" and "skin". This suggests that this environmental crisis has also become a huge business opportunity. However, these kinds of individual actions still need more guidance from authoritative organisations because many such anti-PM2.5 actions are based on rumours or unscientific sources.

Last, but not least, with the living environment degrading day by day, Chinese citizens have begun to question some long-standing cultural traditions, such as setting off fireworks to celebrate lunar New Year ("Spring Festival"). The relevant concept is "fireworks". Setting off firecrackers and fireworks in festivals has been a tradition for over two thousand years in China; therefore, many people had ignored the fact that these devices are sources of noise pollution and air pollution through carbon monoxide discharge. The "airpocalypse" lasting for the past three years has triggered alarm in the country.

From a thorough viewing of all posts, the main content in the public discourse about the air quality involved a wide range of topics, which can be classified into four categories: informational message, commentary message, anti-rumour message, and advertisement. Table 5 shows each category's proportion to the whole data and exemplifying texts. 
Table 5. Weibo content classification

\begin{tabular}{|c|c|c|c|}
\hline Category & Amount & Percentage & Example post \\
\hline $\begin{array}{l}\text { Commentary } \\
\text { message }\end{array}$ & 13922 & $66.3 \%$ & $\begin{array}{l}\text { "[The creditor comes!] In the past } 30 \text { years China's economy has become prosperous, the } \\
\text { privileged class has pocketed enough money and undeniably ordinary people's lives have } \\
\text { also been improved a lot. However this is based on taking usury from environment and } \\
\text { consuming next generations' resources. Today the creditor comes! The whole country is } \\
\text { shrouded in thick smog. And the water and soil pollution is even worse but nobody is aware } \\
\text { of that." }\end{array}$ \\
\hline $\begin{array}{l}\text { Informational } \\
\text { message }\end{array}$ & 5,311 & $25.3 \%$ & $\begin{array}{l}\text { "Beijing, Air Pollution Index: 181, Air quality: [moderately polluted]; PM2.5: } 137 \mu \mathrm{g} / \mathrm{m}^{3}- \\
\text { published at 06:00:00." }\end{array}$ \\
\hline Advertisement & 1339 & $6.7 \%$ & $\begin{array}{l}\text { "The smog has brought a few new things to people's lives. Among others, 'Micro-Shield' } \\
\text { utilises the aerodynamic principles and creative filter net structure, and can filter particulate } \\
\text { as fine as } 0.02 \text { microns. Equipped with this technology, air purifier Philip AC4372 can build } \\
\text { up a real protective screening for your body." }\end{array}$ \\
\hline $\begin{array}{l}\text { Anti-rumour } \\
\text { message }\end{array}$ & 428 & $1.7 \%$ & $\begin{array}{l}\text { " } 30 \text { aged Xiao Zhao heard that black fungus can help get rid of PM2.5 in lungs, so he } \\
\text { cooked a 'black fungus feast' and ate three plates of black fungus. Unexpectedly he got } \\
\text { diarrhoea for days. Yesterday he was diagnosed with acute gastroenteritis. Black fungus can } \\
\text { be absorbed into gastrointestinal system only through digestive system, and cannot do } \\
\text { anything to PM2.5 in respiratory system." }\end{array}$ \\
\hline
\end{tabular}

The informational messages specify those Weibo posts relating to or providing basic information; in this case study, they literally report the air quality and PM2.5 reading in a particular city or location. Such posts account for about $25.3 \%$ of the whole data. Some of these posts were produced by the "share" function through external air-quality monitoring websites or mobile applications, but others were directly published by users.

The content of such messages was usually short and brief reporting of official air-quality readings. A large number of such posts also came with images of local air condition photographed by users and location information automatically generated by Weibo's location service. The other type of content mainly aimed to popularize the common knowledge of PM2.5, and improve people's awareness of environmental protection and public health.

For example, the following two posts exemplify the most common two forms of informational messages.

Wulinglaoqiao: \#Wuhan Air Diary\# 2013-12-31 22:48. [PM2.5] Concentration: 167.0ug/m3. [China AQI index/degree]: 218/heavily polluted. [U.S. AQI index/degree]: 217/very unhealthy (V.U.) [Tips]: Vulnerable and average groups should wear masks and avoid outdoor activities. See image. @wuhanair@KaiwenMap beta version http://t.cn/zjEghhc

Bochi1977: According to a study by Chinese Academy of Social Sciences, from 2009 to 2010, PM2.5 in Beijing had six major sources including secondary inorganic aerosols accounting for 26\%, industrial pollution $25 \%$, coal burning $18 \%$, soil dust $15 \%$, biomass burning $12 \%$ and $4 \%$ of vehicle exhaust and waste incineration.

The first post is an informational reportage of Wuhan's air quality at a particular time (22:48) on a particular day (31 December, 2013). The readings in the content came from a mobile application, "Kaiwen Map", which also yielded an image and attached it to the post. The original post also included the location information such as the street view captured in the image. These informational messages objectively reflected the facts about Wuhan's air quality spatio-temporally and helped ordinary citizens to be more aware of their living environment.

The second post is about the finding of a study conducted by an authoritative Chinese academic institutionChinese Academy of Social Sciences. The content is some scientific facts about the constituents of PM2.5 in Beijing, or in other words, the major contributors to PM2.5 pollution in the capital city. For a long time, people had a wrong sense that the increasing number of cars on the streets should blamed for the deteriorating air quality in big cities. This informational message on one hand corrected the public's misunderstanding, and on the other, pointed out the primary culprits and suggested that the authority should make pertinent intervention policies.

The commentary messages are Weibo posts that often express users' opinion, attitude, or comment toward the issue-related information, or the issue itself. In this case study, such commentary posts were often criticisms specifically relevant to politics, including policies, politicians, government or its performance in particular aspects, such as in regard to the environment, pollution and the like. In this case study, over half of the collected data was composed by such messages, and they instantly reflected citizens' feelings about this air-pollution issue 
in their day-to-day lives.

For example, user “Afternoontea2599" expressed his attitude towards setting off fireworks on Chinese New Year, and his post was circulated hundreds of times on 9 December, 2013:

The New Year is nigh. Here I am calling for changing the existing habits and customs and don't set off fireworks or firecrackers. We have already felt strongly about how dirty Chinese air is becoming, and setting off fireworks and firecrackers will undoubtedly worsen the already grave situation. In 1950's London, the Great Smog caused several thousand deaths. We really don't want to be among them. Let's start with ourselves doing something, for our health, our children and our future!

The post was published one month before the Lunar New Year, the most important holiday for Chinese people when the whole nation has the long-standing tradition of setting off fireworks and firecrackers to celebrate it. Since the air pollution has been deteriorating in recent years, more and more people, including both experts and ordinary citizens, have been calling on the public to reassess the environmental consequences brought by some cultural traditions, for example, celebrating festivals in an environmental-unfriendly manner. The user "Afternoontea2599"quoted above appears to be one of them. Drawing on the tragic experience of London, the user warned that his compatriots should take the problem seriously, and he further called on the public to act immediately.

However, some other people hold different views. As user "undeadGaojie” posted on 31 January, 2014:

Many people are condemning fireworks and crackers! But I have different opinion! Celebrating holidays with fireworks is the only right ordinary people can share with those profiteers and corrupted officials though banning them does help reduce PM2.5! Even if people don't consume fireworks, is the government really determined to harness the environmental pollution? Then please let the officials who consume special supply goods daily enjoy the same hazardous air pollution and noise pollution! Or we can call people to set off fireworks in their living communities! Well! I am ready to perish together with them!

The post was published on New Year's Day. This user viewed this issue from a different angle and pointed out that banning bad cultural habits would not change the status quo because he did not believe that the privileged politicians had the determination to curb the pollution. His tone was pessimistic but did stand for part of the popular sentiment on this issue in the society.

The anti-rumour messages are messages that intend to address some popular rumours widespread on the Internet or in the offline world. For example, in this case study, rumours had been circulating that pig blood and black fungus could help to get rid of PM2.5 in human lungs, but in fact, there is no scientific basis for this claim:

@XidianUniversity: In the past few days the smog has shrouded the whole country. Many anti-smog food "recipes" are emerging on the Internet, including pig blood, duck blood and black fungus which are claimed to clean human lungs and get rid of dusts. But do they really work? According to some experts, PM2.5 is breathed into alveoli while food is digested and absorbed in gastrointestinal system, which can hardly touch the PM2.5 in respiratory system. So the claim is not underpinned by any scientific facts. (Posted on 31 December, 2013)

Another kind of rumour is caused by public misunderstanding of an air-related policy or research. For example, people had misinterpreted experts' claims about the relation between PM2.5 and Chinese cooking habits and condemned the government for not allowing people to cook instead of stipulating effective countermeasures. To address this misunderstanding, officials came out to clarify the truth:

@,Xiaochenshihanhan: On 14 November, Captain Zhong Chonglei of Beijing Environmental Inspection Brigade had a discussion with netizens. He was asked about the famous experiment that claims Chinese cooking for 5 minutes will increase PM2.5 concentration by 20 times: does it mean controlling air pollution will deprive people of the right to feed? Zhong said this is misunderstanding because environmental protection should put people first; the suggestion is advocating healthy lifestyles rather than banning people to eat. (Posted on 6 January, 2014)

It is worth noting that, due to Sina Weibo's special anti-rumour mechanism and some verified user accounts (e.g., "Guikrcrack") that are dedicated to quashing rumours, groundless messages that have the potential to negatively influence a wider group of people will be deleted very quickly after they are published. The surviving rumours only comprise a very small proportion of the total data and are not treated as one separate category here. Thus, the anti-rumour effort by ordinary users is correspondingly reduced.

Advertisements are also wide spread on Weibo. One unanticipated "side effect" of China's deteriorating air quality is the burgeoning market for air-purifying products such as air purifiers, filters and fabric masks. Social 
media, including Weibo, have been viewed as an effective channel for commercial marketing. Among all the collected data, $6.7 \%$ was advertisements of all sorts of products such as skin products, masks and household air purifiers that claim to filter or resolve PM2.5. Although scientists have questioned whether such products can really live up to their claimed virtues, ordinary people are still keen to buy them, even just for psychological comfort.

Here is an example of air purifier advertisement released by a merchant's Weibo account:

@SinanairpurifierPm2-5killer: Last night the outside PM concentration was 52199 (about 521 ug/m3 in national standard), already off the charts. After using Klean air purifier the reading was 1296 (19 ug/m3 in national standard), like the spring breeze! Focus on the practical results when you purchase air purifier! Very specialised equipment, imported from U.S. Full refund if tested as ineffective on the spot 0531-82321688. (Posted on 7 January, 2014)

The post used the common advertising tactic of "before vs. after" to prove the product's amazing effect. Other information such as brand name, place of origin, merchant's promise and phone number constitutes a brief but complete micro-advertisement.

Another example is an advertisement for cleansing soap:

@BaiheAcneExpert: [Smog becomes skin killer] most recent research shows that: smog not only affects human respiratory system but also does a lot of harm to your skin! PM2.5 containing heavy metal and polycyclic aromatic hydrocarbons (PAHs) renders you pores congested with oil and blackheads. Normal facial cleansing products cannot give a thorough cleaning. Now nano silicon soap can help you fix the problem! \#BaiheAcneExpert\# (Posted on 4 February, 2014)

This advertisement introduced the harms of PM2.5 and the limitation of normal facial cleaning products. Then the user claimed that the brand "Baihe" had the right product — nano silicon soap — to fix the problem. From the username and hashtagged words at the end of the post, one can assume that the user is a merchant that has anti-acne skincare products as main product line.

It is hard to evaluate how effective the micro-marketing is because only the sellers have the offline transaction data. Generally, it suffices to say that such products are very popular according to relevant news on Weibo and the traditional media. For example, reports said that during the three days Beijing was heavily smothered by smog, hundreds of air purifiers priced above 10,000 yuan (about 2,100 Australian dollars) were sold per day in shopping malls; in pharmacies, PM2.5 facial masks were always in short supply.

After examining the vibrant discourse practices online, then the question of what social effect they have may be asked. In an attempt to speculate about the impact of this citizens' discursive participation upon the society, a confronting problem also arises: this is an amorphous and ever-evolving subject. Core questions such as "what policy changes resulted from this civil participation?" are especially difficult to answer because policy changes are usually caused by cooperation of multiple factors and there is a lack of evidence to show which part of the change is directly induced by citizens' discursive participation. It can be argued, nonetheless, that vibrant civil participation in environmental issues does alter the policy discussions in that it forces policy makers or stakeholders to realize the problem and take citizens' input into consideration.

In this case study, one important development, which has resulted from citizens' discursive participation, was the establishment of precedents for involvement of ordinary citizens in environmental regulation development. Moreover, regular channels of contact between government, EPBs and citizens that were not normally consulted by the government are being established.

The IPE, a local non-profit environmental organisation, has developed the "China Pollution Map Database". It includes the first public database of water pollution information in China, the China Water Pollution Map, the China Solid Waste Pollution Map and the China Air Pollution Map, in order to monitor corporate environmental performance and to facilitate public participation in environmental governance. On one hand, it aims to promote the disclosure of environmental information to enable communities to fully understand the hazards and risks in the surrounding environment, but on the other, it aims to encourage citizens to watch environmental violations, and urge the government and relevant parties to respond.

For instance, normal user account "Weiwei2010" posted at 10:41AM on 12 June, 2014 (see Figure 2):

In Shandong province, most of Huaneng Power International's subsidiary corporations are discharging excessive pollutants, especially the one in Rizhao City.@ShadongEnvironment@WeihaiEnvironment @IPE-Majun@RizhaoEnvironment@YantaiEnvironmentalProtection 


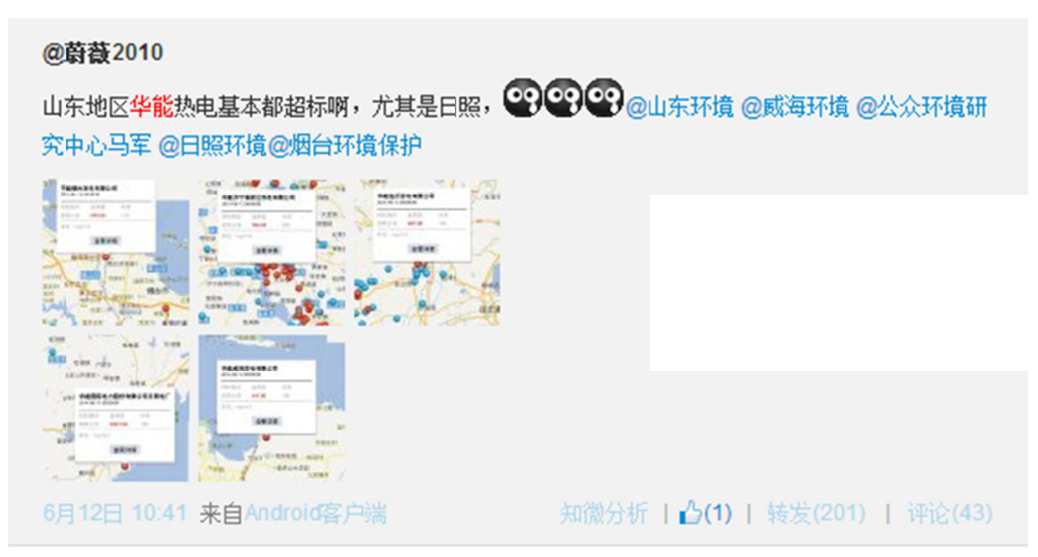

Figure 2. A screenshot of user "Weiwei2010"'s post

The post also attached screenshots of the company's pollution maps in five cities which were obtained from the IPE's pollution database and mentioned the respective local environmental bureaus' accounts as well as the IPE's official account@ @IPE-Majun. @IPE-Majun forwarded the post at 11:39AM urging "the company and its subsidiaries should address the issue as soon as possible”. By 11:46AM @ RizhaoEnvironment replied:

After investigation, the deviating reading of Huaneng Power in Rizhao came from No.4 power unit which has been closed down since 00:35 of 29 May. The unit is undergoing an environmental upgrading and rebuilding which may take about 2 months.

By 8:48AM of 13 June, @YantaiEnvironmentalProtection replied with a promise that they would investigate the issue and announce the result to public immediately after they received it. By 5:28PM on the same day, it released the investigation report on Weibo:

[Response to Yantai Huaneng Power's discharges of excessive pollutants] The company currently has 4 power units (No.4-No.7) among which No.4, No.5, No.7 are not installed with DeNOx facilities, and No. 6 installed with low NOx burner but without environmental assessment yet. In the year No.4 and No.7 units ' upgrading with installation of low NOx burner and SCR DeNOx equipment will be accomplished. Specifically, No.4 unit's low NOx burner installation will be done by August, and the remaining project will be finished by this November.

Later on the same day, @WeihaiEnvironment responded to the IPE's post by addressing the issue in detail on Weibo. By 5:06PM of 17 June, @LinyiEnvironement also responded with specific solutions on its official Weibo account. By the time of writing, four of the five cities' environmental authorities had responded to the issue publicly and the IPE still kept urging Jining's environmental authority to investigate the issue and give the public clear feedback.

In this example, we can clearly see that a channel between the citizens, environmental organisations and environmental authorities has been set up quickly with the aid of social media. Here, the citizen participation has a symbolic meaning: by accessing the disclosed environmental data, even ordinary citizens can directly question the liable companies and force EPBs to take measures. The communication and cooperation between these actors are essential to furthering the public interest and to protecting the civil rights that citizens are entitled to.

In terms of the impact on local government or political institutions, citizens' online discursive participation in environmental issues has had minimal effect on local governments, and not much on the polluting companies either. I have previously stated the economic reasons behind this bureaucratic phenomenon. Undoubtedly, the online public opinion has scared and pressed politicians to carry out their duties, but politicians have rarely been ostracized, and thereby, lost political power for their nonfeasance or noncompliance to environmental regulations. It even can be affirmed that, in China, the power structure could not fall or be seriously altered by the advent of citizen participation. Nonetheless, some partial changes arising from this civil participation can still be expected to improve the public awareness of environmental issues, bring more civil input into the policy-making process, and possibly lead to gradual changes in political structure.

\section{Discussion and Conclusion}

At the very beginning of the PM2.5 dispute in Beijing, Pan Shiyi, a renowned real estate tycoon, utilised an air-quality monitoring mobile application that first revealed the difference between the monitoring readings 
released by the U.S. Embassy in Beijing and those by local weather-forecast station. In most cases, the readings of the U.S. monitoring system were much higher than the local monitoring results. Pan Shiyi's Weibo posts provoked nationwide repercussions, as well as a dramatic increase in downloads of air-pollution monitoring applications. By January 2013, 300 cities' PM2.5 statistics had been made accessible to the public. In the meantime, all kinds of mobile applications for monitoring PM2.5 had been developed. Other generic weather applications also added a PM2.5 monitoring function to their built-in features.

Strictly speaking, such mobile applications are not designed as social networking tools; however, when combined with social media like Weibo, they become "socially oriented mobile applications". Apart from the basic informational function, these apps also provide a "share" function, allowing users to publish the real-time readings to their social spaces. Here, the "share" is not just "share"; it also means to "share and mobilise"-mobilise their friends and associates to monitor their living environment as well. Such mobile technology is helping citizens to perform their civic duty by improving its ability to organise data about their civil lives, and if possible, to mobilise other citizens to take the same action.

Dennis (2007) argues such "technologies of civil society" (p. 19) create new scapes of mobility and social connectivity and foster a potential social restructuring process through shifting patterns in technological applications and user participation. Informational-mediated forms of social practices are becoming increasingly informed through these technologies of connectivity and communication. Users have been enabled to weave their own structures of narrative and creation as designers of new conduits for navigating urban experience (Lane, 2004).

The signs of a growing civil society are visible through the technologies that create the conditions and boundaries for collective action and facilitate collaborative group action. Networks of technologically mediated communications are enabling dispersed and distributed users to engage and participate in complex social webs of presence and action; one of the forms that this complex sociality is contributing to is a more bottom-up and distributed form of civil participation (Dennis, 2007). Grassroots environmental activists using user-driven mobile technologies to gather, create and share information, no matter how informally, can offer the possibility of profound changes to the way in which we engage in our environment and with other inhabitants in it.

Before the wide adoption of mobile applications in recent years, the majority of individuals in China were less aware of the urgent need to preserve the environment and many rural people did not even have any sense of environmental protection (Tilt, 2010). China's expanding elites and middle class were believed to be very content with their privileged social status and unwilling to cede their economic gains in exchange of a resources allocation reform. For most ordinary Chinese people who were still struggling with the goals of achieving economic success, meeting basic life needs, such as housing, education and health care, and enhancing social status, protecting environment was not placed as their top priorities.

That well explained why, for a very long time, public support for environmental protection had been marginalised, despite the already obvious consequences caused by the energy-extensive and high-polluting economic development route. In the perceptions of most citizens, environmental protection was more of a political issue that should be left for the government to deal with and the daily efforts of preserving energy and reducing carbon footprints were a luxury only assigned to those urban elites and the middle class $(\mathrm{Li}, 2013)$. Even though hundreds of environmental protests occasionally broke out over the years, most of them were local-focusing on an environmental issue at a local scale. Few escalated to nationwide movements or induced national policy changes. Often, a not-in-my-backyard mindset was quite common in the general public when dealing with such environmental appeals.

However, with the intensive breakout of environmental problems in recent years, the previous comparatively dispersed environmental forces have been gradually replaced by an emerging green public that embraces a wide range of environmental discourses and a more diversified participating public. In particular, after social media was created, with the advantages of broad reach, connectivity and open discussion, this new technology has facilitated ordinary citizens to receive and disseminate environmental information in a one-stop manner, and to mobilise their fellow citizens within their social networks into action. Since then, this green public has shifted from an elite-based one to a "public" of real sense with wide civil engagement.

When more and more users from different locations publish images of heavily polluted air in the Weibo sphere, the public quickly realise that the issue does not just exist locally, but on a nationwide scale. Only through the public awareness of the severity of the problem can it be possibly raised to a national crisis that unites all involved citizens and spurs them into action, and most importantly, results in these citizens urging the government to respond with effective solutions. Not limited to air pollution, other environmental pollution such 
as soil and underwater pollution has also been raised through social media's aggregating function of public opinion and civic cartography (map-making tools of pollution localities), and thus, has entered the political agenda.

A public is a realm of influence that is created when individuals engage others in communication through conversation, debate or questioning about issues of shared concern or topics that affect a wider community. When people talk about the environment, such a public comes into being in their everyday conversation (be it formal or informal). Since the public sphere is never a monolithic assemblage of all citizens in the abstract, or a uniform communication of reasoned debates, it acknowledges the diverse voices and styles that indicate a robust participatory culture (Cox, 2013).

In this case study, the major voices communicating about the particular environmental issue of air pollution in the green public includes citizens and community groups, environmental organisations, the news media and other social actors such as environmental scientists and public officials. The most common and effective impetus for environmental change comes from the local residents who complain about air pollution and other environmental issues, and who mobilise their compatriots to take the same action. In this case, most citizens are motivated by the noxious smog - which is generated by unsustainable energy consumption or immoral industries' excessive pollution of the atmosphere - to organise resistance to the poor environmental governance of the authority. The tempestuous civil discourse about air pollution succeeded in inducing an institutional change at the policy level. Since then, citizens' continuous monitoring of air quality through mobile applications has actually created a resident civil mechanism that watches the environmental performance of the government and the actual enforcement of environmental regulations.

All these actors are involved in the same collective sphere on environmental topics and contribute to the proliferation of an environmental discourse using differential language and rhetoric, and discursive strategies that are associated with different institutional and political constraints. This environmental discourse contains the whole gamut of linguistic and other symbolic means used for raising awareness of environmental issues (Harre, Brockmeier, \& Mühlhäusler, 1999; also see Yang \& Calhoun, 2007). Different social actors also use environmental discourse for different purposes. This thesis focuses on environmental discourse produced by civil society actors because it expresses a tension between the environment and the state/market and involves civic values such as the basic human rights to live a healthy life. Investigating the civil discourse on environmental topics is also an effective way to examine the watchdog function of civil society and how it allows citizens to monitor policy implementation and put the state in touch with the civil needs.

The relationship between the state and society is always of the scholarship's inquiry when investigating Chinese non-governmental organisations (NGOs) in civil society. Li (2013) pessimistically argues that, subject to political coercion from the state, China's poorly developed civil society adds more obstacles to the cause of environmental protection by blocking free avenues of public advocacy, civic engagement, and the development of non-governmental organisations. Regardless of how promising the environmental organisations may appear in recent years, they are commonly still constrained in their efforts to influence policy-making and most of them are confronted with insufficient funding and staffing, a lack of public support, limited local resources, antagonism from the relevant industries, and restrictions and surveillance imposed by the state and local governments.

However, Howell (2004) has long anticipated that the state corporatist framework cannot adequately interpret the new developments in Chinese society, such as the emerging stratum of civil-society type organisations that work on specific marginalised fields. This is because the decentralisation and the streamlining of state agencies down to the local level has left governance processes too fragmented to pursue a corporatist agenda or contain the proliferation of societal groups and activities. Calhoun \& Yang (2007) resonate with Howell that despite the government's important role in fostering the green public, much more credit should be given to the agency of the non-state actors that is, citizens and civil organisations.

This empirical study further proves that this growing green public, if operating positively and effectively, can establish a benign interactive circuit among the involved stakeholders, and foster a healthy relational model between the state and civil society. And the development of social media has connected the role and responsibility of the state, environmental organisations and citizens. In this process, social norms, values and discourse of environmental protection came into shape, and accordingly, ideologies and cultural frames for environmental movements have begun to crystallise in China with the institutionalisation of processes, new positions and roles $(\mathrm{Ke}, 2014)$. Increasingly, this environmental activism on social media has been coming into contact with the central decision-making institutions, directly or indirectly, and has occasionally been involved in decision-making processes within the state. 


\section{References}

Boyd, A. (1994). Broadcast journalism, techniques of radio and TV news. Waltham, Mass: Focal Press.

Calhoun, C., \& Yang, G. (2007). Media, civil society, and the rise of a green public sphere in China. China Information, 21(2), 211-236. https://doi.org/10.1177/0920203X07079644

Carter, N. T., \& Mol, A. P. J. (2006). China's environmental governance in transition. Environmental Politics, 15(2), 149-170. https://doi.org/10.1080/09644010600562765

Cox, J. R. (2013). Environmental Communication and the Public Sphere (3rd ed.). Thousand Oaks, CA: SAGE.

Dennis, K. (2007). Technologies of civil society: Communication, participation and mobilization. Innovation, 20(1), 19-34. https://doi.org/10.1080/13511610701197817

Gardiner, B. (2014). Air of revolution: how activist and social media scrutinise city pollution. The Guardian. Retrieved from http://www.theguardian.com/cities/2014/jan/31/air-activists-social-media-pollution-city

Greenpeace. (2012). Dangerous breathing. Retrieved from http://www.greenpeace.org/eastasia/publications/reports/climate-energy/2012/air-pollution-health-economic

Harre, R., Brockmeier, J., \& Mühlhäusler, P. (1999). Greenspeak: A study of environmental discourse. Thousand Oaks, CA: SAGE.

Hemmi, A., \& Crowther, J. (2013). Learning environmental activism through social networking sites? The Journal of Contemporary Community Education Practice Theory, 4(1), 1-7. Retrieved from http://concept.lib.ed.ac.uk/index.php/Concept/article/view/218

Hook, L. (2013). China's environmental activists. FT Magazine. Retrieved from http://www.ft.com/cms/s/2/00be1b66-1f43-11e3-b80b-00144feab7de.html

Howell, J. (2004). New directions in civil society: Organizing around marginalized interests. In Howell, J. (Ed.), Governance in China (pp. 143-171). Lanham, MA: Rowman \& Littlefield.

$\mathrm{Ke}, \mathrm{X}$. (2014). The civic engagement of social media users in air quality issues in Beijing, China (Master's thesis). Retrieved from http://lib.dr.iastate.edu/etd/13900/

Lane, G. (2004). Social tapestries: Public authoring and civil society. Proboscis, 9(7), 1-9. Retrieved from http://proboscis.org.uk/publications/SNAPSHOTS_socialtapestries.pdf

Li, X. (2013). The weak link: Diagnosing political and social factors in China's environmental issue. Chinese Studies, 2(4), 178-184. https://doi.org/10.4236/chnstd.2013.24029

Lo, C. W. H., \& Fryxell, G. E. (2003). Enforcement styles among environmental protection officials in China. Journal of Public Policy, 23(1), 81-115. https://doi.org/10.1017/S0143814X03003040

Lotspeich, R., \& Chen, A. (1997). Environmental protection in the People's Republic of China. Journal of Contemporary China, 6(14), 33-59. https://doi.org/10.1080/10670569708724264

Schofer, E., \& Granados, F. G. (2006). Environmentalism, globalization and national economies, 1980-2000. Social Forces, 85(2), 965-991. https://doi.org/10.1353/sof.2007.0024

Schwartz, F. (2003). What is civil society? In F. Schwartz \& S. Pharr (Eds.), The state of civil society in Japan. London: Cambridge University Press. https://doi.org/10.1017/CBO9780511550195.003

Song, S. (2014). China discloses official air pollution data in response to appeals from environmental groups. International Business $\quad$ Times. Retrieved from http://www.ibtimes.com/china-discloses-official-air-pollution-data-response-appeals-environmental-groups1552912

Tilt, B. (2010). The struggle for sustainability in rural China. New York, NY: Columbia University Press.

Wodak, R. (1999). Critical discourse analysis at the end of the 20th Century. Research on Language and Social Interaction, 32(1-2), 185-193. https://doi.org/10.1080/08351813.1999.9683622

Xinhua News (2012, July 05). Foreign embassies' air data issuing inaccurate, unlawful: official. Retrieved from http://news.xinhuanet.com/english/china/2012-06/05/c_131633044.htm 


\section{Note}

Note 1. In Plight and way-out: A sociological perspective on the Straw Man phenomenon in China's environmental protection, Chuansong Ma uses the term "straw man" to describe local environmental authorities' dwarfed situation in which they are often required by the local governments to convoy the polluting enterprises to insure both high GDP growth and tax revenues.

\section{Copyrights}

Copyright for this article is retained by the author(s), with first publication rights granted to the journal.

This is an open-access article distributed under the terms and conditions of the Creative Commons Attribution license (http://creativecommons.org/licenses/by/4.0/). 